\title{
Belief does not entail a reasoning disposition
}

\section{Simon Wimmer ${ }^{1}$ (10}

Received: 9 April 2021 / Accepted: 11 October 2021 / Published online: 16 December 2021

(c) The Author(s) 2021

\begin{abstract}
Are there any dispositions one must have if one believes $p$ ? A widespread answer emphasizes the role of beliefs in reasoning and holds that if one believes $p$, one must be disposed to treat $p$ as true (rely on $p$ /use $p$ as a premise) in one's reasoning. I argue that this answer is subject to counterexamples.
\end{abstract}

Keywords Belief · Reasoning disposition · Philosophy of mind

\section{Introduction}

What exactly one is disposed to do if one believes $p$ varies considerably. Whether one is disposed to pick up an umbrella if one believes that it will rain, for instance, depends on whether one has appropriate means-end beliefs and desires (Geach 1971). In light of this, we may wonder: are there any dispositions one must have if one believes $p$ ? One common answer emphasizes the role of beliefs in reasoning: one's beliefs appear to supply one with premises one can exploit in reasoning towards lemmas/conclusions. According to this answer, if one believes $p$, one must be disposed to treat $p$ as true (rely on $p$ /use $p$ as a premise) in one's reasoning. Call this the reasoning disposition claim. ${ }^{1}$

Variants of the reasoning disposition claim are widespread. For instance, Ross and Schroeder (2014) say that "at least part of the functional role of belief is that believing [...] $p$ defeasibly disposes the believer to treat $p$ as true in her reasoning" (pp. 2678). For Ross and Schroeder, this means that a reasoning disposition is essential to

\footnotetext{
1 The label is inspired by Ross and Schroeder (2014)'s reasoning disposition account of belief. The reasoning disposition claim, however, is endorsed also by theorists, like Williamson, who do not endorse Ross and Schroeder's reasoning disposition account.
}

$凶$ Simon Wimmer

simon.wimmer@tu-dortmund.de

1 Technische Universität Dortmund, Fakultät Humanwissenschaften und Theologie, Institut für Philosophie und Politikwissenschaft, Emil-Figge-Str. 50, 44227 Dortmund, Deutschland

1 The label is inspired by Ross and Schroeder (2014)'s reasoning disposition account of belief. The reasoning disposition claim, however, is endorsed also by theorists, like Williamson, who do not endorse Ross and Schroeder's reasoning disposition account. 
believing $p$ (pp. 270, 272). And from this it arguably follows that necessarily, if one believes $p$, one is defeasibly disposed to treat $p$ as true in one's reasoning. ${ }^{2}$ As another example, consider Williamson (2017) who restricts his claim to practical reasoning. According to Williamson, "belief is a sort of state disposed to make the premises of practical reasoning": "if you have no disposition whatever to rely on it as a premise in practical reasoning, it is no belief" (p. 173). ${ }^{34}$

My aim here is to argue against the reasoning disposition claim. More carefully, I will focus on one way of understanding that claim that clarifies how the reasoning disposition is individuated.

In general, there are two contrasting views of how dispositions are individuated. The first individuates a disposition by the pair of its stimulus condition and manifestation. ${ }^{5}$ On this option, 'treat $p$ as true' specifies the reasoning disposition's manifestation and 'in one's reasoning' its stimulus condition so that the stimulus condition is a (suitable) activity of reasoning. However, following Vetter (2015, pp.63-7), I will assume that a disposition is instead individuated solely by its manifestation. ${ }^{6}$ On this view, the infinitival clause 'to treat $p$ as true in one's reasoning' specifies the reasoning disposition's manifestation only.

I will argue that, given the manifestation-only view of dispositions, the reasoning disposition claim is false. My argument will proceed by considering three ways of interpreting the infinitival clause that specifies the reasoning disposition's manifestation: either the prepositional phrase 'in one's reasoning' functions as a kind of locative modifier (Sect. 2), or as introducing the antecedent of a conditional (Sect. 3), or it is redundant (Sect. 4). On all of these interpretations, it is possible to believe $p$ without being disposed to treat $p$ as true in one's reasoning, and the reasoning disposition claim suffers from counterexamples. I conclude (Sect. 5) by briefly lifting my restriction to a manifestation-only view of dispositions to show that my counterexamples generalize given at least the specific version of the stimulus-manifestation view due to Wasserman (2011).

Before turning to my argument, it might be helpful to make two further clarifications regarding its scope. First, we might wonder whether my arguments against the reasoning disposition claim generalize to Ross and Schroeder's view. For whilst they talk about a defeasible disposition to treat $p$ as true in one's reasoning, I have formulated the reasoning disposition claim so as to concern a disposition to treat $p$ as

\footnotetext{
2 The entailment here depends on the common assumption that if it is essential for $x$ to be $F$, then necessarily, if $x$ exists, $x$ is $F$. This assumption is endorsed by views that take essences to be definable in terms of necessity (Cowling 2013; Wildman 2013) as well as views that take essences to be more basic than (at least some) necessities (e.g. Fine 1994; Hale 2002).

3 Williamson seems to talk about relying on a belief state rather than relying on a proposition one believes. For present purposes, the difference between these claims does not matter. My argument in this paper applies either way.

4 Further endorsements of the reasoning disposition claim can be found in Smithies (2012) and Weisberg (2020) among others.

5 Or, if the disposition is multi-track, by several such pairs.

6 One reason for making this move, noted also by Manley and Wasserman (2008, pp. 72-3), is that typical adjectives used to ascribe dispositions in natural language, such as 'fragile,' 'transmissible' and 'irascible,' only specify the disposition's manifestation: breaking, being transmitted, and getting angry. Thus, taking natural language at face value, we have reason to adopt the manifestation-only view of dispositions.
} 
true in one's reasoning (notice the absence of 'defeasible'). Fortunately, however, this difference does not affect my argument. ${ }^{7}$ Ross and Schroeder's talk of defeasibility highlights that the reasoning disposition is subject to specific masking conditions. ${ }^{8}$ As they put it, this disposition "is overridden when the costs of mistakenly acting as if $p$ are salient" (2014, p. 279; see also p. 267). ${ }^{9}$ When one's reasoning disposition is overriden in such a high stakes case, one relies on one's credence rather than one's belief; one does not treat $p$ as true in one's reasoning, but only as likely to degree $d$ (where the value of $d$ is fixed by one's credence). Given this, a defeasible disposition to treat $p$ as true in one's reasoning is a disposition to treat $p$ as true in one's reasoning subject to specific masking conditions. But, as we will see, these masking conditions do not obtain in the examples I will rely on. Thus, whether the reasoning disposition is subject to Ross and Schroeder's specific masking conditions makes no difference to whether my examples are counterexamples to the claim that belief entails a reasoning disposition; my argument generalizes to Ross and Schroeder's view. ${ }^{10}$

A second clarification regarding the scope of my argument turns on the modal force of the reasoning disposition claim. Following the spirit of extant discussions, I formulate this claim as a claim of necessity: it is meant to be true at all metaphysically possible worlds that if one believes $p$, one is disposed to treat $p$ as true in one's reasoning. The counterexamples below falsify this claim of necessity, by showing that it is metaphysically possible to believe $p$ without being disposed to treat $p$ as true in one's reasoning. However, since most of these examples are, admittedly, unusual cases, they are, by and large, not apt for falsifying weaker claims in the vicinity of the reasoning disposition claim, such as the claim that it is true at all worlds like, or normal relative to, the actual world that if one believes $p$, one is disposed to treat $p$ as true in one's reasoning. ${ }^{11}$ So, for all I say here, weakening the modal force of the reasoning disposition claim may well yield defensible alternatives. Whether it in fact does, however, is a question I leave for another occasion.

\footnotetext{
7 Ross and Schroeder sometimes also call the reasoning disposition a default disposition (e.g. p. 267). In doing so, they appear to treat 'defeasible' and 'default' as equivalent. At other points, Ross and Schroeder take the reasoning disposition to be automatic (e.g. fn.14, p. 270). Like its defeasibility, the reasoning disposition's automaticity does not undermine my arguments below, since my arguments show that no disposition to treat $p$ as true in one's reasoning of any kind, automatic or not, is required for believing $p$.

8 A masking condition is one where an object retains a disposition, despite being prevented from manifesting it. Compare a fragile vase in bubble wrap: the bubble wrap does not remove the vase's fragility, but prevents it from manifesting.

9 Weisberg (2020, p. 4), who also endorses the reasoning disposition claim, suggests that one's disposition may also be overridden if the implications of $p$ are surprising.

10 An alternative interpretation has Ross and Schroeder say that the manifestation, not the disposition is defeasible. The reasoning disposition, then, is a disposition to defeasibly treat $p$ as true in one's reasoning. Perhaps, this manifestation is to be understood in analogy with a conditional, so that the reasoning disposition is a disposition to treat $p$ as true in one's reasoning if no defeating conditions are present, where conditions like being in a high stakes case are among the defeating conditions. My discussion of the claim that the reasoning disposition is a disposition to verify a conditional below suggests that this option also faces significant challenges.

11 One exception is the counterexample to the strict conditional interpretation of the reasoning disposition in Sect. 3.2. This case involves a perfectly ordinary case and so generalizes also to the strict conditional interpretations of the modally weakened claims in the text.
} 


\section{The locative interpretation}

How exactly should we understand the reasoning disposition claim? One important choice point concerns what contribution we take the prepositional phrase 'in one's reasoning' to make. On one natural interpretation, the prepositional phrase 'in one's reasoning' functions as a special kind of post-verbal locative modifier. The next subsection will explain this interpretation. The argument against it is then developed in two further steps (Sects. 2.2 and 2.3).

\subsection{A special kind of post-verbal locative modifier}

Post-verbal locative modifiers express properties of an individual and a place of some sort. For instance, 'Alice swam her laps in the pool' says, roughly, that there was an event of Alice swimming that was located in the pool. ${ }^{12}$ Similarly, 'one treats $p$ as true in one's reasoning' says, roughly, that there is an event of one treating $p$ as true located in an event of one reasoning.

Interpreting the claim that an event of Alice swimming was located in the pool is straightforward. The pool occupies a certain region of space $r$. The event at issue was located in the pool because it occurred in a subregion of $r$. But this interpretation does not generalize to the claim that an event of one treating $p$ as true is located in an event of one reasoning. The region at issue here is not a spatial one. Instead, I suggest, the event of one treating $p$ as true is located in an event of one's reasoning insofar as it is a part of such an event. ${ }^{13}$

This interpretation receives independent confirmation from the fact that the preposition 'in' is regularly used to talk about parthood. Culinary contexts provide some examples. Consider: 'What's in Mapo Tofu? Sichuan pepper for sure.' The natural interpretation of the response is that Sichuan pepper is a part of Mapo Tofu. Contexts in which we are concerned with the content of books provide further examples: e.g. 'The chapter on assertion in Knowledge and Its Limits is worth reading.' The natural interpretation here is that the mentioned chapter is a part of Knowledge and Its Limits.

As an alternative to my interpretation, we may be tempted to interpret 'in one's reasoning' as a post-verbal durative modifier which, roughly, locates an eventuality within a temporal region. Admittedly, the preposition 'in' often features in such modifiers. Consider 'John read the book in ten minutes,' for instance. However, the verb phrase 'treat $p$ as true' does not in general combine with durative modifiers featuring the preposition 'in;' rather, it combines with durative modifiers featuring 'for' or 'throughout':

\footnotetext{
12 I here focus on external locatives, where an event is located in a place of some kind. There are also internal locatives where some participant of an event is located in a place of some kind; for instance, 'The cook prepared the chicken in a Marijuana sauce' which says, roughly, that the chicken is located in the sauce as part of a preparation event. And, finally, there are frame-setting locatives, which typically occur clause-initial: e.g. 'In Sweden, Fred was cold' which says, roughly, that whilst in Sweden, Fred was cold. See Ernst (2016) and Maienborn (2001) for discussion.

13 Compare Fine (2010): "When one object is a part of another, there is a sense in which it is in the othernot in the sense of being enclosed by the other, as when a marble is in an urn, but more in the sense of being integral to the other" (p. 560).
} 
1. John treated $p$ as true for too long/throughout the day / \# in hours.

This suggests that the phrase 'in one's reasoning' as it occurs in 'one treats $p$ as true in one's reasoning' does not function as a post-verbal durative modifier.

The locative interpretation of 'in one's reasoning' allows us to understand the reasoning disposition as the disposition to be such that there is an event of one treating $p$ as true that is part of an event of one reasoning. ${ }^{14}$ This understanding fuels a twostep argument against the reasoning disposition claim. First, it allows us to argue (Subsect. 2.2) that being disposed to treat $p$ as true in one's reasoning entails being disposed to reason. And that entailment then allows us (Subsect. 2.3) to construct a counterexample to the reasoning disposition claim involving a subject that believes $p$, but is not disposed to reason, and so, by the entailment, not disposed to treat $p$ as true in their reasoning.

\subsection{A disposition to reason}

In addition to the locative interpretation of 'in one's reasoning', my argument for the claim that being disposed to treat $p$ as true in one's reasoning entails being disposed to reason uses two principles governing disposition ascriptions.

The first connects dispositions whose manifestation involves a parthood relation amongst events with dispositions whose manifestation involves a conjunction of events. It says that:

2. Necessarily, if one is disposed to be such that there is an event of one ming that is part of an event of one ning, then one is disposed to be such that (there is an event of one ming and an event of one $n$ ing). ${ }^{15}$

So, for instance, suppose Alice is disposed to swim as part of competing for gold, i.e. disposed to be such that there is an event of Alice swimming that is part of an event of her competing for gold. Then the principle predicts that Alice is disposed to swim and compete for gold, i.e. disposed to be such that (there is an event of Alice swimming and an event of her competing for gold).

Support for this prediction comes from infelicitous conjunctions that assert an instance of 2.'s antecedent, whilst negating a corresponding instance of its consequent. Consider:

3. \# Alice is disposed to swim as part of competing for gold, but not disposed to swim and compete for gold.

A natural explanation of the infelicity here is available in three steps. It says, first, that it is impossible for Alice to have the disposition to swim as part of competing

\footnotetext{
14 In parsing this disposition ascription, care must be taken to read it as de dicto. It does not imply that there is an event of one treating $p$ as true that is part of an event of one reasoning such that one is disposed to be such that it obtains.

15 The principle does not require that the ming events that verify the first existential quantification are distinct from the $n$ ing events that verify the second. For all the principle says, they may be identical: Alice, for instance, may compete by swimming, and this may mean that her competing and her swimming are one event under two descriptions. Compare Hornsby (1980) and Anscombe (1963, §§23-6). In this context, it is also worth emphasizing that the principle is formulated using parthood, rather than proper parthood, and so allows the events verifying the antecedent to be identical.
} 
for gold, whilst failing to have a disposition to swim and compete for gold; second, that competent speakers of (philosophical) English recognize this impossibility and so know that 3. is necessarily false; and third, that in light of this knowledge, they take an utterance of 3. to be infelicitous. Evidently, the first step in this explanation entails principle 2.

Principle 2. is also validated by various semantics for disposition ascriptions. As an example, consider Vetter (2015, p.73) (see also Aimar 2018, p.15). ${ }^{16}$ For Vetter, disposition ascriptions are close in flavour to possibility claims. ${ }^{17}$ 'The vase is fragile,' for instance, is true just in case there are a few worlds at which the vase breaks, where context determines which worlds are relevant and how many of them count as 'a few'. Applying this semantics, 'Alice is disposed to swim as part of competing for gold' is true just in case there are a few contextually relevant worlds at which Alice is such that there is an event of her swimming that is part of an event of her competing for gold. But of course, at any such world Alice will be such that there is an event of her swimming and an event of her competing for gold. So, if Alice is disposed to be such that there is an event of Alice swimming that is part of an event of her competing for gold, then Alice is disposed to be such that (there is an event of Alice swimming and an event of her competing for gold). Generalizing, we get principle 2. ${ }^{18}$

Thanks to the locative interpretation of 'in one's reasoning' and principle 2., having the reasoning disposition - the disposition to be such that (there is an event of one treating $p$ as true that is part of an event of one reasoning) — entails being disposed to be such that (there is an event of one treating $p$ as true and an event of one reasoning). This in turn entails, by way of a second principle, that one is disposed to reason. According to this second principle, dispositions distribute over conjunction:

4. Necessarily, if one is disposed to be such that (there is an event of one ming and an event of one $n$ ing), then one is disposed to $m$ and disposed to $n$.

To illustrate, suppose Alice is disposed to swim and compete for gold, i.e. disposed to be such that there is an event of her swimming and an event of her competing for gold. Then the principle predicts that she is both disposed to swim and disposed to compete for gold.

\footnotetext{
16 Maier (2016)'s semantics also validates the principle and so does Aimar (2018)'s, at least on the assumption that 'easily,' which plays a crucial role in Aimar's account (see section 3.2), obeys a version of the principle too.

Note that the semantic theories I refer to are developed as semantics of dispositional adjectives like 'fragile', 'irascible', and others ending in '-ble'. However, since the technical locution 'is disposed to' is meant to capture the properties objects have in virtue of satisfying dispositional adjectives (Aimar 2018, p.3), it is natural to use the same semantics to evaluate disposition ascriptions using the 'is disposed to'-construction. 17 A complication I ignore here is that Vetter gives another semantics for adjectives like 'breakable' (as opposed to 'fragile' and 'irascible') that uses a weaker modal force than the one in the text, namely existential quantification over contextually relevant worlds. However, this semantics validates the principles in the text just as well as the semantics discussed in the text does. So, for brevity, I omit discussion of Vetter's second semantics.

18 Vetter's semantics for disposition ascriptions, like those cited in the previous footnote, is contextualist. Thus, whether a disposition ascription is true depends on the context in which it is uttered. In light of this, let me emphasize that principle 2. (just like the second principle below) is intended to hold within individual contexts; in particular, the antecedent and consequent of the embedded conditional are to be evaluated at the same context. For all I say here, shifts in context may yield cases where the antecedent is true as evaluated at the initial context, whilst the consequent is false at the shifted context.
} 
As was the case for principle 2., evidence that this prediction is correct comes from infelicitous conjunctions. Consider:

5. \# Alice is disposed to swim and compete for gold, but not disposed to swim (compete for gold).

Principle 4. is also validated by various semantics for disposition ascriptions. Returning to Vetter's semantics, 'Alice is disposed to swim and compete for Gold' is true just in case there are a few contextually relevant worlds at which Alice is such that she swims and competes for gold. But of course, at any such world both 'Alice swims' and 'Alice competes for gold' are true. So, if Alice is disposed to swim and compete for gold, then she is disposed to swim and she is disposed to compete for gold. Generalizing, we get principle 4 .

Given principles 2. and 4., as well as the locative interpretation of 'in one's reasoning,' having the reasoning disposition entails that one is disposed to reason. Thus, lacking the disposition to reason entails lacking the reasoning disposition. I will now exploit this fact to construct a counterexample to the reasoning disposition claim: a possible case where the subject believes $p$, but is not disposed to reason, and so not disposed to treat $p$ as true in their reasoning.

\subsection{The counterexample}

Given the entailment from lacking the disposition to reason to not being disposed to treat $p$ as true in one's reasoning, the answer to whether the reasoning disposition claim is true depends on whether there are any subjects that are not disposed to reason, but nonetheless believe some $p$. I think there are such subjects.

Here is one: Imagine a creature, Numan, resembling an ordinary human, except that she has a slightly different neural architecture. Hers is more compartmentalized than that of an ordinary human. Her perceptual processing and perceptual recognitional capacities are realized by one part of her brain; her memories by another; her speech comprehension and control by yet another; and her reasoning by still another one.

Even though Numan's affective, cognitive, and perceptual processes are realized in distinct parts of Numan's brain, they interact and make her functionally indistinguishable from a human, at least in normal circumstances. But, what if certain parts of her brain are damaged or removed? Let's imagine, in particular, that the part of her brain realizing her reasoning is removed, perhaps by targeted surgery, and her brain has not (yet) reorganized in such a way as to realize her reasoning in a different part. Now, Numan is unable to reason, for she lacks the neural architecture required for it. Crucially, this inability to reason seems to entail that she is not disposed to reason either. As she's missing a realizer for her reasoning and so is unable to reason, her disposition to reason is not merely masked or otherwise prevented from manifesting, unlike the fragility of a vase that is masked by some bubble wrap.

Despite being unable to reason, however, Numan is functionally indistinguishable from an ordinary human in a wide variety of ways. Suppose, for instance, that she believed (and even knew) $p$ before her targeted surgery and that, even after her surgery, she remains (i) in a position to remember $p$; (ii) disposed to consciously judge that $p$ is true; (iii) disposed to assert $p$ (for instance, when directly asked $p$ ?); (iv) disposed to act 
so as to satisfy those of her desires concerning which $p$ represents an available means of satisfaction (with the exception of actions that require reasoning, of course); and (v) disposed to be surprised upon (apparently) discovering that $\neg p$. After all, the parts of the brain realizing Numan's memory, perceptual recognition, speech comprehension and control, and much else were left intact by the surgery. Given the wide variety of ways in which Numan is functionally indistinguishable from an ordinary human who believes $p$, and given that she believed (and even knew) $p$ before her targeted surgery, it is hard to deny that she still believes $p$, even after her surgery. And this is so, despite the fact that she is not disposed to reason. But, if she believes $p$ without being disposed to reason, then the entailment from not being disposed to reason to not being disposed to treat $p$ as true in one's reasoning tells us that she believes $p$ without being disposed to treat $p$ as true in her reasoning. Thus, Numan is a counterexample to the reasoning disposition claim.

\section{The conditional interpretation}

One way to undermine the argument of the last section is to interpret 'in one's reasoning' as introducing the antecedent of a conditional, rather than as a post-verbal locative modifier. Given this, treating $p$ as true in one's reasoning no longer entails being the agent of an event that is part of an event of one reasoning. Hence my argument based on Numan's case is, at least at first glance, moot. But, what conditional should we appeal to?

\subsection{A material conditional?}

One option interprets the disposition to treat $p$ as true in one's reasoning as the disposition to satisfy the material conditional 'if one reasons, then one treats $p$ as true.' 19 However, this option trivializes the reasoning disposition claim. For one satisfies the material conditional at issue if one does not reason. But then, if one is disposed not to reason, one is disposed to treat $p$ as true in one's reasoning. Depending on what is required for one to be disposed not to reason, a wide range of individuals, inanimate or not, now satisfy the necessary condition for believing $p$ which the reasoning disposition claim imposes. For instance, as it has no mind, a stone is disposed not to reason and so, on the present option, is disposed to treat any $p$ as true in its reasoning.

At first glance, the fact that a stone is intuitively not disposed to treat any propositions as true in its reasoning raises a red flag for this proposal. However, defenders of the reasoning disposition claim might reply that the material conditional interpretation's odd consequences are outweighed by its potential in insulating the reasoning disposition claim from counterexample. Pursuing this reply, they might say that, by lacking the neural realizer required for her to reason, Numan is not only not disposed to reason, but also disposed not to reason, and so disposed to treat $p$ as true in her

\footnotetext{
19 Plausibly, the antecedent should be further restricted to reasoning where $p$ is relevant or something similar. I omit this complication in the text, as it makes no difference to my argument.
} 
reasoning. The material conditional interpretation thus undermines Numan's status as a counterexample to the reasoning disposition claim.

That the material conditional interpretation trivializes the reasoning disposition claim does not mean that it ascribes beliefs to stones and entities like them. ${ }^{20}$ As the reasoning disposition claim is merely a necessary condition for believing $p$, the stone's being disposed to treat $p$ as true in its reasoning does not force defenders of the reasoning disposition claim to mistakenly predict that it believes $p$. However, the material conditional interpretation does suffer from other shortcomings, in addition to predicting that the stone is disposed to treat $p$ as true in its reasoning, in light of which even defenders of the reasoning disposition claim should reject it. In particular, the material conditional interpretation undermines several of the motivations for the reasoning disposition claim noted in the literature (e.g., by Ross and Schroeder 2014, pp. 275-85).

Let me illustrate this by way of an example from Ross and Schroeder's discussion. (I discuss two further examples taken from their discussion in fn.21.). According to Ross and Schroeder (ibid., pp. 276-7), the reasoning disposition claim helps to explain a datum they call correctness, viz. that believing $p$ when $p$ is true constitutes being right about $p$, whereas believing $p$ when $p$ is false constitutes being wrong about $p$. Given the reasoning disposition claim, they suggest, there is a sense in which believing entails getting things right or wrong. For if $p$ is true, then being disposed to treat $p$ as true in one's reasoning amounts to being disposed to reasoning in a way that gets things right about $p$. And if $p$ is false, then being disposed to treat $p$ as true in one's reasoning amounts to being disposed to reasoning in a way that gets things wrong about $p$. So, the reasoning disposition explains why believing $p$ entails getting things right (wrong) if $p$ is true (false). (To explain the further claim that believing $p$ constitutes being right (wrong) about $p$ if $p$ is true (false), rather than just entailing it, Ross and Schroeder appear to rely on their claim that being disposed to treat $p$ as true in one's reasoning is essential to believing $p$.)

The material conditional interpretation undermines this explanation in at least two ways. First, it entails that being disposed to treat $p$ as true in one's reasoning does not amount to being disposed to reasoning in a way that gets things right or wrong about $p$. On the material conditional interpretation, a stone/Numan is disposed to treat $p$ as true in their reasoning, but not disposed to reason, and so not disposed to reasoning in any way. A related problem arises when we consider a creature, Tuman, who is just like Numan, except that she has no view about whether $p$. Since she has no view on the matter, Tuman is neither right nor wrong about $p$, regardless of how things turn out regarding $p$. But, like Numan, she is disposed to treat $p$ as true in her reasoning. Consequently, the material conditional interpretation predicts that having a reasoning disposition does not entail that one is right (wrong) about $p$ if $p$ is true (false). These two problems highlight that, on the material conditional interpretation, the reasoning disposition amounts to less than we might expect. In light of this, however, maintaining

$\overline{20}$ I am grateful to an anonymous reviewer for pushing me to clarify this point. 
an entailment from believing $p$ to the reasoning disposition does not help to explain why believing $p$ constitutes getting things right (wrong). ${ }^{21}$

In sum, I suggest that the material conditional interpretation should be rejected even by defenders of the reasoning disposition claim. Due to trivializing the reasoning disposition claim, it not only predicts dispositions we intuitively do not ascribe, but also undermines various motivations meant to support the reasoning disposition claim.

\subsection{A strict conditional?}

One alternative to the material conditional interpretation, which avoids trivializing the reasoning disposition claim, interprets the disposition to treat $p$ as true in one's reasoning as the disposition to satisfy the strict conditional 'necessarily, if one reasons, one treats $p$ as true.' This strict conditional embeds the earlier material conditional under a necessity operator 'necessarily,' interpreted as a universal quantifier whose domain is restricted to the metaphysically possible worlds. The strict conditional 'necessarily, if one reasons, then one treats $p$ as true' is true just in case the embedded material conditional is true at all metaphysically possible worlds.

This option may not trivialize the reasoning disposition claim, as even a stone may reason at some metaphysically possible world and so fail to vacuously satisfy the strict conditional. However, the strict conditional interpretation still faces difficulties. John,

${ }^{21}$ Let me mention two further motivations Ross and Schroeder cite. The first turns on the datum that belief is subject to the consistency norm "where A is a small set of related propositions that are jointly inconsistent, it is rationally impermissible to simultaneously believe every proposition in A" (ibid., p.283). Ross and Schroeder argue that, thanks to the reasoning disposition claim, someone who believes jointly inconsistent propositions risks treating jointly inconsistent propositions as true in their reasoning; this risk is one rational people would avoid; and so, rational people would not believe jointly inconsistent propositions. The second motivation turns on the datum that it is rational to believe a proposition $p$ only if one's evidence significantly favours $p$ over its negation. Their explanation of this datum (ibid., pp. 282-3) turns on the claim that if $p$ is a proposition whose probability on one's evidence is not significantly higher than that of $\neg p$, then being disposed to treat $p$ as true in one's reasoning would do more harm than good. After all, one would thereby run a significant risk of treating a false proposition as true in one's reasoning.

Both explanations fail on the material conditional interpretation. For consider Tuman again: given the material conditional interpretation, she is vacuously disposed to treat all propositions as true in her reasoning, regardless of how likely they are on her evidence or whether they are jointly inconsistent. So, Tuman is disposed to treat $p$ and $\neg p$ as true in her reasoning. Yet, intuitively, Tuman does not thereby risk treating jointly inconsistent proposition as true in her reasoning; she is, after all, unable to reason. Similarly, take an arbitrary proposition $p$ whose probability on Tuman's evidence is not significantly higher than that of its negation. Tuman is vacuously disposed to treat $p$ as true in her reasoning. But, intuitively, she does not thereby run a significant risk of treating a false proposition as true in her reasoning; again, she is unable to reason. So, important links in Ross and Schroeder's explanations fail. The reasoning disposition claim, on the material conditional interpretation, does not help to explain the two data at issue.

Now, we might object to the arguments in this footnote by saying that 'in $x$ 's reasoning' be interpreted as the antecedent of a material conditional even outside of the context of the reasoning disposition claim. This would enable us to insist that Tuman does risk treating jointly inconsistent propositions as true in her reasoning and does run a significant risk of treating a false proposition as true in her reasoning, although she does so vacuously in both cases. However, this reply is of little help. For one, it predicts that the stone too risks treating jointly inconsistent propositions as true in its reasoning and runs a significant risk of treating a false proposition as true in her reasoning. But these predictions are obviously false; the stone runs no such risks. For another, even if we conceded that there was some kind of risk the stone runs, it is unclear why that kind of risk should matter normatively and impose rational requirements on subjects, as is required by Ross and Schroeder's explanations. 
for instance, believes $p$, but is not such that necessarily, if he reasons, he treats $p$ as true. For at some metaphysically possible world, one where, instead of believing $p$, he believes $\neg p$ or suspends judgement about $p$, he reasons, but does not treat $p$ as true. This possibility also makes it hard to see how John could be disposed to be such that necessarily, if he reasons, he treats $p$ as true. ${ }^{22}$

The intuition here is hard to pin down without a specific semantics of disposition ascriptions. But, as an example of a semantics which validates the intuition, consider Aimar (2018). ${ }^{23}$ For her, disposition ascriptions are possibility claims. 'The vase is fragile,' for instance, is true just in case there is some world at which the vase breaks easily, where context determines the domain of 'some.' Applying this semantics, 'John is disposed to be such that necessarily, if John reasons, he treats $p$ as true' is true just in case there is some contextually relevant world at which John is easily such that necessarily, if John reasons, he treats $p$ as true. But there is no such world. Since there is some metaphysically possible world where John reasons, but does not treat $p$ as true, the strict conditional is false at all worlds. Thus, John is a counterexample to the reasoning disposition claim: he believes $p$, but is not disposed to treat $p$ as true in his reasoning.

Admittedly, this particular counterexample can be avoided. Defenders of the reasoning disposition claim can insist that they need not look at all worlds at which John reasons in determining whether he is disposed to treat $p$ as true in his reasoning. Instead, they can restrict their attention to worlds at which John reasons and some further condition obtains. ${ }^{24}$ This is, in effect, to introduce a restriction into the antecedent of the strict conditional used by the strict conditional interpretation. On the resulting restricted strict conditional interpretation, the disposition to treat $p$ as true in one's reasoning is the disposition to satisfy the strict conditional 'necessarily, if one reasons and some further condition obtains, one treats $p$ as true.'

Unfortunately, we have reason to be sceptical of this reply. To see why, consider how we might fill in the added condition. Looking at the counterexample described above, a natural option is to appeal to belief. Then, the disposition to treat $p$ as true in one's reasoning is the disposition to be such that necessarily, if one reasons and believes $p$, one treats $p$ as true. This avoids the counterexample described above. For the fact that there is some metaphysically possible world where John reasons, but does not treat $p$ as true because he believes $\neg p$ or suspends judgement about $p$, no longer makes the strict conditional false at all worlds. So, for all I have said, the strict conditional is true at some worlds, in particular at those worlds relevant for ascribing the reasoning disposition to John.

However, a restriction to worlds at which John reasons and believes $p$ does not suffice to ward off other counterexamples. Consider, for instance, what could happen in a high stakes case: John could reason, but, despite believing $p$, only treat $p$ as soand-so likely, rather than as true. Or consider what could happen if John feels stressed out: his belief could fail to come to his mind, so that he merely treats $p$ as an open

\footnotetext{
22 The same reasoning also applies to Numan. So, the strict conditional interpretation does not even avoid my previous counterexample.

23 Both Maier (2016)'s and Vetter (2015)' semantics also validate the intuition.

24 I thank an anonymous reviewer for this journal for bringing this response, and in particular the restriction, discussed below, to worlds at which John reasons and believes $p$, to my attention.
} 
possibility, rather than as true. These examples show that there are metaphysically possible worlds where John reasons and believes $p$, but does not treat $p$ as true. But given this, the strict conditional on which the restricted strict conditional interpretation relies is false at all worlds. Hence, John is, yet again, a counterexample to the reasoning disposition claim: he believes $p$, but is not disposed to treat $p$ as true in his reasoning.

Defenders of the strict conditional interpretation might try to ward off the counterexamples just sketched by adding further restrictions. They might restrict their attention to worlds at which John not only reasons and believes $p$, but is also in a low/normal stakes case and is not feeling stressed. But it is hard to see what restriction could avoid counterexamples altogether. For instance, even given the restrictions just mentioned, the existence of worlds at which John's belief fails to come to his mind and he merely treats $p$ as an open possibility because he is sleepy still makes John a counterexample to the reasoning disposition claim. And if defenders of the strict conditional interpretation decide to impose a blanket restriction along the lines of 'no defeating conditions are present', they owe us an explanation of what these conditions are. Absent such an explanation, we are either not in a position to evaluate whether these conditions fulfil their task or may reasonably suspect that they save the reasoning disposition claim from counterexample (if at all) only by trivializing it. For, of course, being disposed to be such that necessarily, one treats $p$ as true if one reasons and is no counterexample to this disposition ascription $i s$ entailed by believing $p$.

Granted, the points just made do not conclusively settle the issue. Still, they highlight a significant burden for defenders of the reasoning disposition claim intent on pursuing the strict conditional interpretation. They must somehow specify a suitable restriction on the antecedent of the strict conditional that avoids both counterexamples and triviality.

\subsection{A variably strict conditional?}

The material conditional interpretation trivializes the reasoning disposition claim and the strict conditional interpretation faces difficulties too. A final option interprets the disposition to treat $p$ as true in one's reasoning as the disposition to satisfy a variably strict conditional, e.g. a would-counterfactual or normality conditional. A variably strict conditional ' $\phi>\psi$ ' is treated as a universal quantifier whose domain is restricted to some subset of the metaphysically possible $\phi$-worlds. ' $\phi>\psi$ ' is true evaluated at a world iff all of the metaphysically possible $\phi$-worlds in the relevant subset are $\psi$-worlds. For a would-counterfactual, the domain is restricted to the metaphysically possible $\phi$-worlds closest to the world of evaluation (e.g. Lewis 1973). For a normality conditional, the domain is restricted to the metaphysically possible $\phi$-worlds normal relative to the world of evaluation (e.g. Smith 2007).

One important question for this version of the reasoning disposition claim is how the variably strict conditional's embedding under a disposition predicate affects the restriction we impose on the set of metaphysically possible $\phi$-worlds. This question is hard to answer in a way that avoids counterexamples.

To illustrate, suppose we again adopt Aimar's semantics for disposition ascriptions and that we interpret the variably strict conditional as a would-counterfactual. On these 
assumptions, 'one is disposed to treat $p$ as true in one's reasoning' is true just in case at some contextually relevant world $w$ one is easily such that at metaphysically possible worlds closest to $w$ at which one reasons, one treats $p$ as true. Depending on what $w$ is like, however, it is easy to find counterexamples to the reasoning disposition claim so understood.

Consider yourself in a dreamless sleep, falsely believing that Liege is in France. Suppose the domain of 'some' is restricted to worlds at which you are intrinsically just like at the actual world. Suppose also that at the actual world and so at all worlds in the domain of 'some', a wizard has shrunk himself so that he lives inside you and watches over you. This wizard has the power to make you believe only truths, by either extinguishing your false beliefs or replacing them with suitably related true beliefs, and reliably successfully exercises this power should you be about to reason. Now, at at least some metaphysically possible worlds closest to the worlds in the domain of 'some' where you reason, you do not falsely believe that Liege is in France and so do not treat that proposition as true. Thus, on this way of developing the present option, you are not disposed to treat the proposition that Liege is in France as true in your reasoning. So, you are a counterexample to the reasoning disposition claim. ${ }^{25}$

This counterexample depends neither on the specific domain restriction on 'some' nor on appeal to the would-counterfactual. ${ }^{26}$ Of course, we may attempt to restrict the domain of 'some' to worlds where no wizards are present. But notice that, on Aimar's semantics, the restriction on the domain of 'some' is meant to be supplied by context. It would be surprising if every context delivered a wizard-excluding restriction. So, we can reasonably expect there to be some contexts in which the counterexample arises.

Moreover, if we interpret the variably strict conditional as a normality conditional rather than as a would-counterfactual, we get counterexamples by describing the case so that it is normal for you to have a shrunk wizard inside you. (Imagine yourself in a fantasy novel.) Given this, at least at some metaphysically possible worlds normal relative to the worlds in the domain of 'some' where you reason, you do not falsely believe that Liege is in France and so do not treat that proposition as true.

There is obviously more to be said about the case I am using. I do not intend it to preclude interpreting the disposition to treat $p$ as true in one's reasoning as the disposition to satisfy a variably strict conditional. Rather, I take the example to highlight a burden for defenders of the reasoning disposition claim intent on pursuing the present option. They must, first, say how the variably strict conditional's embedding under a disposition predicate affects the restriction we impose on the set of metaphysically possible $\phi$-worlds and, second, show that the resultant view avoids counterexamples like the case in the last few paragraphs.

\footnotetext{
25 Note that this example is not a convincing counterexample to the reasoning disposition claim if we understand 'in one's reasoning' as a post-verbal locative modifier. On that understanding the example may be understood as featuring an intrinsic fink for your disposition to treat the proposition that Liege in France as true in your reasoning. For there does exist a world where you are intrinsically just like in our imagined world, but also treat the proposition that Liege is in France as a premise in your reasoning; for instance, a world where another wizard blocks the wizard inhabiting you from successfully exercising their power.

26 The counterexample resembles Martin (1994)'s fink cases, which involve a disposition that will be eliminated in circumstances that would commonly trigger its manifestation.
} 


\section{The redundancy interpretation}

Both of my arguments against the reasoning disposition claim so far relied on the reasoning disposition's being a disposition to treat $p$ as true in one's reasoning. The two arguments differed merely in how they interpreted the prepositional phrase 'in one's reasoning'. A radical reply to both arguments, then, takes this prepositional phrase to be redundant or, alternatively, simply deletes it from our specification of the reasoning disposition. The reasoning disposition, on this reply, is just the disposition to treat $p$ as true (or rely on $p /$ use $p$ as a premise).

There are two options regarding how to interpret treating $p$ as true, a substantive and a modest one. The modest interpretation has it that reasoning plays no special role in the manifestation of the reasoning disposition. To treat $p$ as true, the thought is, one need not make use of it in one's reasoning. For instance, consciously judging that $p$ is true is a way of treating $p$ as true, but does not require reasoning. So, not having a disposition to reason does not prevent one from having a disposition to treat $p$ as true. Importantly, however, the modest interpretation gives up on the idea that there is a link between belief and reasoning. So, from my perspective, the modest interpretation does not undermine my argument, but rather concedes defeat.

What about the substantive interpretation? This interpretation emphasizes the use of $p$ as a premise. On this interpretation, the reasoning disposition is a disposition to treat $p$ as a premise. Now, at first glance, treating $p$ as a premise seems to require reasoning. What else might treating $p$ as a premise be, if not a bit of reasoning from that premise to some lemma/conclusion? But if that is what treating $p$ as a premise amounts to, then a disposition to reason is required for a disposition to treat $p$ as a premise. It thus seems that the substantive interpretation does not avoid my earlier argument, despite dropping the prepositional phrase 'in one's reasoning' in specifying the reasoning disposition's manifestation.

This argument against the substantive interpretation is too quick, however. To see this, let's draw an analogy between reasoning, on the one hand, and proving in a system of natural deduction such as Fitch, on the other. Consider a very simple proof of the conjunction $P \wedge P$ from the premise $P$.

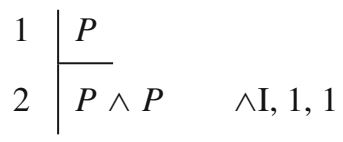

The proof as a whole involves a transition from a premise to a conclusion, from $P$ in the first line to $P \wedge P$ in the second. But the first line on its own involves no such transition. The first line stipulates that $P$ is to be the premise of a proof by way of the horizontal line underneath it. This stipulation by itself does not require one to then complete the proof or take any further steps towards its completion. Still, by writing $P$ in the first line and drawing a horizontal line underneath it, one has, in an important sense, treated $p$ as a premise.

By analogy, we might think that treating $p$ as a premise does not require any reasoning from $p$ to a lemma or conclusion. Treating $p$ as a premise might be the mental equivalent of writing $P$ in the first line of the above proof and drawing a 
horizontal line underneath it. So, a disposition to treat $p$ as a premise does not seem to require a disposition to reason. Thus, arguments along the lines of Sect. 2 are blocked. Moreover, the substantive interpretation spelled out in this way does not give up on emphasizing the role beliefs play in reasoning: belief disposes one to do something that plays a central role in reasoning; reasoning normally involves a transition from things one treats as premises to some lemmas/conclusions.

However, we have reason to be sceptical of this interpretation of the reasoning disposition claim too. For it seems at least possible, if not likely, that our creature, having lost its disposition to reason, also loses its disposition to treat things as premises. That might be for either of two reasons. First, we might stipulate that Numan's capacity to treat something as a premise is, just like her reasoning capacities, realized by the part of her brain that was surgically removed.

Second, even if this was not the case, and her capacity to treat something as a premise was realized elsewhere, it is worth noting that treating $p$ as a premise, understood in analogy with writing $P$ in the first line of the above proof and drawing a horizontal line underneath it, plays a central role in reasoning, but not in much else. Indeed, it appears to be pointless to treat $p$ as a premise, unless one goes on to reason from $p$ to some lemma/conclusion. But, Numan cannot do that, since the parts of her brain that realize such transitions have been removed. So, for Numan it appears pointless to treat $p$ as a premise. Yet given this, we would expect it to be at least possible for her not to be disposed to treat $p$ as a premise. Thus, Numan's case still suggests that a reasoning disposition, even one specified as a disposition to treat $p$ as a premise only, is not required to believe $p$.

\section{Concluding remarks}

My aim here has been to argue against the claim-endorsed in some form by Ross and Schroeder (2014) and Williamson (2017), among others - that to believe $p$, one must be disposed to treat $p$ as true in one's reasoning. Strictly speaking, my argument has been conditional on individuating dispositions, following Vetter (2015), by their manifestations only and so interpreting the clause 'to treat $p$ as true in one's reasoning' as specifying only the reasoning disposition's manifestation. Even given this restriction in the scope of my argument, however, its result is significant. For if the reasoning disposition claim requires a specific metaphysics of dispositions, that is both interesting and worrisome. Anyone inclined towards a manifestation-only view of dispositionssuch as myself-has reason to reject the reasoning disposition claim.

In addition, my counterexamples generalize, given at least some versions of the view that a disposition is individuated by the pair of its manifestation and stimulus condition. By way of conclusion, let me illustrate this by considering one way of developing that view. On Wasserman (2011, p. 445)'s account, $x$ is disposed to $m$ in $s$ at a situation $\alpha$, where $m$ is a manifestation and $s$ a stimulus condition, just in 
case $x m \mathrm{~s}$ at many $s$-situations. ${ }^{27}$ The $s$-situations are a subset of the situations at which the disposition's stimulus condition, $s$, obtains: at all situations in this subset $x$ is intrinsically just like at $\alpha$ and the $\alpha$-laws of nature obtain. 'Many $F$ s are $G$ ' is true just in case the number of $F$ s that are $G$ divided by the number of $F$ s exceeds a contextually-determined threshold; depending on context, this threshold may be quite low.

If Wasserman's view is right, one is disposed to treat $p$ as true in one's reasoning at a situation $\alpha$ just in case one treats $p$ as true at many situations at which (i) the $\alpha$-laws of nature obtain, (ii) one is intrinsically just like at $\alpha$, and (iii) one engages in a (suitable) activity of reasoning. One satisfies the right-hand-side of this biconditional, moreover, just in case the number of worlds at which (i) to (iii) are satisfied and one treats $p$ as true divided by the number of worlds at which (i) to (iii) are satisfied exceeds a contextually-determined threshold.

But now return to Numan. Anyone intrinsically like her is barred from reasoning, for lack of a neural realizer of reasoning or suitable replacement of such a realizer. Given this, however, there are no situations at which (i) to (iii) are satisfied. The number of such situations is 0 . So, the number of situations at which (i) to (iii) are satisfied and one treats $p$ as true is also 0 . Yet 0 divided by 0 is undefined. So, we do not get a number that exceeds the contextually-determined threshold, whatever the threshold may be. Wasserman's view thus does not predict that Numan is disposed to treat $p$ as true in her reasoning. If this is right, Numan remains a counterexample to the reasoning disposition claim, even if we abandon a manifestation-only view of dispositions. My argument against the reasoning disposition claim generalizes to at least some versions of the view that 'treat $p$ as true' specifies the reasoning disposition's manifestation, whilst 'in one's reasoning' specifies its stimulus condition. ${ }^{28}$

Funding Open Access funding enabled and organized by Projekt DEAL.

Open Access This article is licensed under a Creative Commons Attribution 4.0 International License, which permits use, sharing, adaptation, distribution and reproduction in any medium or format, as long as you give appropriate credit to the original author(s) and the source, provide a link to the Creative Commons licence, and indicate if changes were made. The images or other third party material in this article are included in the article's Creative Commons licence, unless indicated otherwise in a credit line to the material. If material is not included in the article's Creative Commons licence and your intended use is not permitted by statutory regulation or exceeds the permitted use, you will need to obtain permission directly from the copyright holder. To view a copy of this licence, visit http://creativecommons.org/licenses/by/4.0/.

\footnotetext{
27 I here gloss over the fact that Wasserman's right-hand-side appeals to $x$ ming in rather than at many $s$-situations. This detail will not matter for my purposes.

Wasserman, both in his 2011 and in joint work with David Manley (Manley and Wasserman 2008), seems to endorse Vetter's claim that a disposition is individuated by its manifestation only. I nonetheless characterize Wasserman's view as a way of developing the popular view of dispositions because it takes 'in $s^{\text {' as it }}$ occurs in a disposition ascription of the form ' $x$ is disposed to $m$ in $s$ ' to specify the stimulus condition of the target disposition.

28 For their helpful comments I am grateful to Thomas Crowther, Richard Holton, Tristan Kreetz, Hemdat Lerman, Guy Longworth, Jennifer Nagel, Giulia Martina, Johannes Roessler, Eva Schmidt, Jessica Struchhold, and Tim Williamson, audiences in Dortmund, Durham, Toronto and Tübingen, as well as two anonymous referees for this journal.
} 


\section{References}

Aimar, S. (2018). Disposition ascriptions. Philosophical Studies. https://doi.org/10.1007/s11098-0181084-9.

Anscombe, G. E. M. (1963). Intention. Cambridge, MA: Harvard University Press.

Cowling, S. (2013). The modal view of essence. Canadian Journal of Philosophy, 43(2), 248-266. https:// doi.org/10.1080/00455091.2013.827395

Ernst, T. (2016). Modification of stative predicates. Language, 92(2), 237-274. https://doi.org/10.1353/lan. 2016.0042

Fine, K. (1994). Essence and Modality: The Second Philosophical Perspectives Lecture. Philosophical Perspectives, 8, 1-16. https://doi.org/10.2307/2214160

Fine, K. (2010). Towards a theory of part. Journal of Philosophy, 107(11), 559-589. https://doi.org/10. 5840/jphil20101071139

Geach, P. T. (1971). Mental acts: their content and their objects. [1st ed.] reprinted with a new preface. Studies in philosophical psychology. London, New York: Routledge and K. Paul; Humanities Press.

Hale, B. (2002). The Source of Necessity. Noûs, 36(s16), 299-319.

Hornsby, J. (1980). Actions. London: Routledge and Kegan Paul.

Lewis, D. (1973). Counterfactuals. Cambridge, MA: Harvard University Press.

Maienborn, C. (2001). On the Position and Interpretation of Locative Modifiers. Natural Language Semantics, 9(2), 191-240. https://doi.org/10.1023/A:1012405607146

Maier, J. (2016). Modal Predicates. Linguistics and Philosophy, 39(6), 443-457.

Manley, D., \& Wasserman, R. (2008). On Linking Dispositions and Conditionals. Mind, 117(465), 59-84. https://doi.org/10.1093/mind/fzn003

Martin, C. B. (1994). Dispositions and Conditionals. Philosophical Quarterly, 44(174), 1-8.

Ross, J., \& Schroeder, M. (2014). Belief, Credence, and Pragmatic Encroachment. Philosophy and Phenomenological Research, 88(2), 259-288.

Smith, M. (2007). Ceteris Paribus Conditionals and Comparative Normalcy. Journal of Philosophical Logic, 36(1), 97-121. https://doi.org/10.1007/s10992-006-9030-2

Smithies, D. (2012). The Normative Role of Knowledge. Noûs, 46(2), 265-288. https://doi.org/10.1111/j. 1468-0068.2010.00787.x

Vetter, B. (2015). Potentiality: From dispositions to modality. Oxford philosophical monographs (1st ed.). New York, NY: Oxford University Press.

Wasserman, R. (2011). Dispositions and Generics. Philosophical Perspectives, 25(1), 425-453. https://doi. org/10.1111/j.1520-8583.2011.00223.x

Weisberg, J. (2020). Belief in Psyontology. Philosophers. Imprint, 20(11), 27.

Wildman, N. (2013). Modality, Sparsity, and Essence. The Philosophical Quarterly, 63(253), 760-782. https://doi.org/10.1111/1467-9213.12059.

Williamson, T. (2017). Acting on Knowledge. In J. Adam Carter, E. C. Gordon, \& B. Jarvis (Eds.), Knowledge First: Approaches in Epistemology and Mind. Oxford: Oxford University Press. https://doi.org/ 10.1093/oso/9780198716310.003.0008.

Publisher's Note Springer Nature remains neutral with regard to jurisdictional claims in published maps and institutional affiliations. 